\title{
A Case of Thoracic Lordosis in a Cat
}

\author{
Başar Ulaş Sayılkan'1*, Taylan Önyay2, Umut Burak Ağan1, Yücel Meral1, Duygu Dalgın1 \\ ${ }^{1}$ Department of Veterinary Internal Medicine, Faculty of Veterinary Medicine, OndokuzMayıs University, Samsun, \\ Turkey \\ ${ }^{2}$ Department of Veterinary Surgery, Faculty of Veterinary Medicine, OndokuzMayıs University, Samsun, Turkey \\ Email: ^basarulas.sayilkan@omu.edu.tr
}

How to cite this paper: Sayllkan, B.U., Önyay, T., Ağan, U.B., Meral, Y. and Dalgın, D. (2022) A Case of Thoracic Lordosis in a Cat. Open Journal of Veterinary Medicine, 12, 1-5.

https://doi.org/10.4236/ojvm.2022.121001

Received: December 8, 2021

Accepted: January 27, 2022

Published: January 30, 2022

Copyright $\odot 2022$ by author(s) and Scientific Research Publishing Inc. This work is licensed under the Creative Commons Attribution International License (CC BY 4.0).

http://creativecommons.org/licenses/by/4.0/

\begin{abstract}
A $1.8 \mathrm{~kg}$, seven months old, intact, female, mix-breed cat was referred with dyspnea and paresis. Since the patient was in such a condition that she was too incapable of the operation, treatment for dyspnea was performed. The patient has abdominal enlargement. When the respiratory stress of the patient decreased, a radiograph was taken and lordosis was found. Medical treatment was applied, because the general condition was impaired. Lordosis is the excessive curvature of a certain number of vertebrae in the neck and back region. Congenital thoracic lordosis has been described as a highly progressive and low vital capacity disease in humans and cats. Because it compresses the lung, it can cause dyspnea in patients and rhythm disturbances in the heart. This case represents a severe example of untreatable and unmanageable lordosis encountered in a cat.
\end{abstract}

\section{Keywords}

Anomaly, Congenital, Dyspnea, Thoracic Lordosis

\section{Introduction}

Lordosis is the excessive curvature of a certain number of vertebrae in the neck and back region [1]. Congenital spinal malformations are common in small animals. Its symptoms vary from patient to patient. For example, symptoms are sometimes characterized by pain, while sometimes myelopathy, radiculopathy, and gross spinal deformities can occur. However, spinal malformations may not always show neurological findings, and the clinician can detect this anomaly by chance. A good anamnesis should be obtained from patients with neurological findings, and a good neurological examination should be done besides general examination. The localization of spinal information is a differential diagnosis for the cause of neurological findings. The underlying cause of spinal malformations 
is often unknown, but genetic predisposition is thought to contribute. It is thought that other potential causes may be caused by metabolic disease, and especially folate, teratogen drugs, and toxins can cause anomalies [2]. Dogs and cats with congenital spinal malformations can have simultaneous congenital anomalies that affect other systems or other areas of the central nervous system. Especially when considering anesthesia or surgery, it is necessary to fully identify all possible anomalies to reduce unforeseen complications [3]. This case report aims to emphasize the approach algorithm for the patient with lordosis, which is a congenital anomaly.

\section{Case Description}

A 7-months old, $1.8 \mathrm{~kg}$, the intact female mix-breed cat was brought to OMU Animal Hospital Department of Internal Medicine with a complaint of respiratory distress and weakness in the hind legs; CRT (Capillary filling time) was 3 seconds, dehydration rate $>8 \%$, heart rate: 220 beats/minute and arrhythmic, respiratory rate: 40 breaths/minute, lymph nodules were asymmetrical. Lung auscultation was abnormal. The patient has abdominal enlargement. The patient was immediately moved inside an oxygenated chamber due to severe respiratory distress and dyspnea and only removed from there for brief periods of time for further evaluations. The patient was paraplegic and neurological examination showed signs of a T3-L3 lesion; the cat had no deep pain perception in either hindlimb, and flexor reflex evaluations elicited mass reflex in both legs. Patellar reflexes of both legs and anal reflex were exaggerated due to abnormal morphology of the body and chest and the presence of dyspnea. The thorax x-ray showed a gross vertebral anomaly in addition to pectus excavatum. Cranial and caudal lobe areas in the L/L radiograph were severely constricted by the spine and showed bronchiolar interstitial signs. The Cobb angles were measured at the two greatest deviation sites, shown at Figure 1. The patient underwent abdominal ultrasonography to investigate the cause of the abdominal enlargement, but no abnormality was found in the abdomen. As a result of the complete blood count, neutropenic leukopenia was detected (Table 1). No negative findings were found in serum biochemistry analysis (Table 2).

At the treatment stage; Prednisolone (Prednol; Mustafa Nevzat) $1 \mathrm{mg} / \mathrm{kg}$ BID iv Clindamycin (Klindan; Bilim) $10 \mathrm{mg} / \mathrm{kg}$ SID iv, Isotonic $0.9 \% \mathrm{NaCl} 100 \mathrm{ml}$ iv, Dextrose $5 \% 100 \mathrm{ml}$ iv solution $10 \mathrm{ml} / \mathrm{kg}$ iv Fluticasone propionate (Flixotide; GSK) $250 \mathrm{mcg}$ q12h and Salbutamol (Ventolin; GSK) $200 \mathrm{mcg}$ q6h inhaler was applied.

The patient's respiratory and circulatory systems were already compromised at the initial presentation, and palliative treatment did not improve her condition. Despite being put inside an oxygenated chamber, the dyspnea progressively worsened.

\section{Discussion}

Lordosis is the innate curvature of a certain number of vertebrae in the lordless 
neck and back region [1]. Congenital spinal malformations are common in small animals. Its symptoms vary. For example, symptoms are sometimes characterized by pain, while sometimes myelopathy, radiculopathy, and gross spinal deformities can occur [3] [4]. Dyspnea, right ventricular hypertrophy, pulmonary artery hypertension, and dysphagia symptoms are observed due to thoracic compression [5]. Partial paralysis may develop in the hind legs [1]. Although it is seen in all cats, it has been reported that it is more common in Manx breed cats [6]. In addition, one study was emphasized that thoracic anomalies are more common in Bengal cats than Domestic Shorthair breed cats [4].

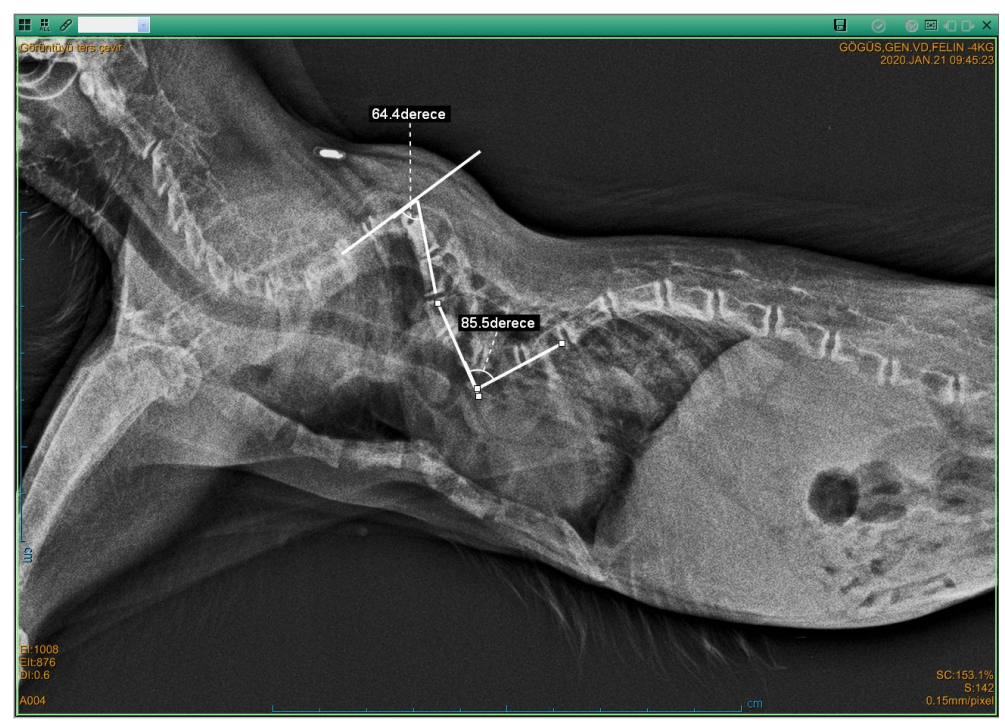

Figure 1. The L/L radiogram of the case. Note the extreme angulation present between T4-T5 and T8-T9 vertebrae. There is also pectus excavatum which is evident between the 4 th and 5 th sternebrae.

Table 1. Complete blood count values.

\begin{tabular}{|c|c|c|c|}
\hline WBC $\left(10^{9} / \mathrm{L}\right)$ & 5.12 & $\operatorname{MCV}(\mathrm{fl})$ & 46.80 \\
\hline $\operatorname{NEU}\left(10^{9} / \mathrm{L}\right)$ & 3.48 & $\mathrm{MCH}(\mathrm{pg})$ & 16.50 \\
\hline LYM $\left(10^{9} / \mathrm{L}\right)$ & 1.48 & $\mathrm{MCHC}(\mathrm{g} / \mathrm{dl})$ & 354.00 \\
\hline $\operatorname{MON}\left(10^{9} / \mathrm{L}\right)$ & 0.10 & RDW-CV (\%) & 0.18 \\
\hline $\operatorname{EOS}\left(10^{9} / \mathrm{L}\right)$ & 0.06 & RDW-SD (fL) & 33.00 \\
\hline BAS $\left(10^{9} / \mathrm{L}\right)$ & 0.00 & $\operatorname{PLT}\left(10^{9} / \mathrm{L}\right)$ & 387.00 \\
\hline $\mathrm{RBC}\left(10^{12} / \mathrm{L}\right)$ & 9.67 & MPV (fL) & 12.20 \\
\hline HGB (g/dl) & 16.00 & PDW (\%) & 15 \\
\hline HCT (\%) & 45 & PCT (ml/L) & 4.70 \\
\hline
\end{tabular}

(WBC: White Blood Cell, NEU: Neutrophil, LYM: Lymphocyte, MON: Monocyte, EOS: Eosinophil, BAS: Basophil, RBC: Red Blood Cell, HGB: hemoglobin, HCT: Hematocrit, MCV: Mean Corpuscular Haemoglobin, MCH: Mean Corpuscular Haemoglobin, MCHC: Mean Corpuscular Haemoglobin Concentration, RDW-CV: Red Blood Distribution Width Coefficient of Variation, RDW-SD: Red Blood Cell Distribution Width Standart Deviation, PLT: Platelet, MPV: Mean Platelet Volume, PDW: Platelet Distribution Width, PCT: Plateletcrit). 
Table 2. Serum biochemical values.

\begin{tabular}{lccc}
\hline ALP (U/L) & 32 & GGT (U/L) & 2 \\
ALT (U/L) & 35.3 & UREA (mg/dl) & 22 \\
AST (U/L) & 28 & CREA (mg/dl) & 1.8 \\
AMY (U/L) & 1200 & P (mg/dl) & 4.5 \\
\hline
\end{tabular}

(ALP: Alkaline phosphatase, ALT: Alanine aminotransferase, AST: Aspartate amino transferase, AMY: Amylase, GGT: Gamma-glutamyl transferase, UREA: Urea Nitrogen), CREA: Creatinine, P: Phosphorus).

A Cobb angle greater than $10^{\circ}$ is generally considered to be a lordosis [7]. In this case, the Cobb angle measurement was as Figure 1 at the site of greatest deviation, but the deformity was so obvious that the measurement was hardly necessary for diagnosis.

It causes dyspnea by significantly reducing lung capacity in humans and animals. It will also make food intake difficult due to esophageal compression, and therefore the patient will have to eat small amounts of liquid foods [8]. Given the extreme curvatures of the spine in our patient, both respiration, circulation were compromised. The patient could not properly consume solid food, so a soft/liquid diet mix had to be administered in small portions several times a day.

Radiography, CT, and MRI can detect scoliosis. Myelography or MRI are also used to detect spinal cord compression [2] [6]. MRI and contrast CT studies were not considered in this case due to the anesthetic risk being too high. Also, simple two-way radiography was enough to diagnose the condition.

In severe and advanced cases, surgical intervention may require more than one intervention in a long period of time. The patient's condition can change with intervention in some cases. Some patients may be eligible for surgical intervention. However, potential postoperative complications include quadriplegia, prolonged ventilatory support, cardiac arrest, and death [1] [9].

Given the patient's lack of deep pain perception and spine morphology, surgery was an unrealistic option, given the severity of our patient. Despite being kept in an oxygenated chamber and given a constant rate infusion of pain medication (lidocaine, ketamine, and butorphanol), quality of life kept deteriorating. Euthanasia was presented as an option but was refused. Despite the explained condition, due to financial reasons, the cat for house care took. Supportive treatment was recommended. The owner said the patient died in a follow-up phone call two days later.

\section{Conclusion}

This case is a good example of inoperable and untreatable spinal cord malformation, in which no recourse can give a favorable outcome. We think the quality of life determines the final decision and if it is constantly deteriorating despite all treatment, ending the patient's suffering via euthanasia is the only sensible choice. 


\section{Conflicts of Interest}

The authors declare no conflicts of interest regarding the publication of this paper.

\section{References}

[1] Lee, M.S., Taylor J. and Lefbom, B. (2014) Congenital Thoracic Lordosis and Scoliosis in a Cat. Journal of Feline Medicine and Surgery, 16, 703-707. https://doi.org/10.1177/1098612X13514975

[2] Crowe, Y.C., Child, G., Lam, R. and McGregor, R. (2019) Congenital Block Vertebrae and Intervertebral Disc Protrusion in a Young Cat. Journal of Feline Medicine and Surgery Open Reports, 5, No. 2. https://doi.org/10.1177/2055116919868037

[3] Westworth, D.R. and Sturges, B.K. (2010) Congenital Spinal Malformations in Small Animals. Veterinary Clinics of North America: Small Animal Practice, 40, 951-981. https://doi.org/10.1016/j.cvsm.2010.05.009

[4] Charlesworth, T.M. and Sturgess, C.P. (2012) Increased Incidence of Thoracic Wall Deformities in Related Bengal Kittens. Journal of Feline Medicine and Surgery, 14, 365-368. https://doi.org/10.1177/1098612X12437351

[5] Newitt, A., German, A.J. and Barr, F.J. (2008) Congenital Abnormalities of the Feline Vertebral Column. Veterinary Radiology \& Ultrasound, 49, 35-41. https://doi.org/10.1111/j.1740-8261.2007.00314.x

[6] Lavely, J.A. (2006) Pediatric Neurology of the Dog and Cat. Veterinary Clinics of North America: Small Animal Practice, 36, 475-501. https://doi.org/10.1016/j.cvsm.2005.12.009

[7] Komsta, R., Osiński, Z., Dębiak, P., Twardowski, P. and Lisiak, B. (2019) Prevalence of Pectus Excavatum (PE), Pectus Carinatum (PC), Tracheal Hypoplasia, Thoracic Spine Deformities and Lateral Heart Displacement in Thoracic Radiographs of Screw-Tailed Brachycephalic Dogs. PLoS ONE, 14, e0223642. https://doi.org/10.1371/journal.pone.0223642

[8] Gögüs, A., Talu, U. and Hamzaoglu, A. (2001) One-Stage Surgical Correction of Congenital Thoracic Lordosis-Report of 2 Cases. Acta Orthopaedica Scandinavica, 72, 413-418. https://doi.org/10.1080/000164701753542096

[9] Havlicek, M., Mathis, K.R., Beck, J.A. and Allan, G.S. (2009) Surgical Management of Vertebral Malformation in a Manx Cat. Journal of Feline Medicine and Surgery, 11, 514-517. https://doi.org/10.1016/j.jfms.2008.11.005 